\title{
Is Mehrabad Airport a Brownfield Site?
}

\author{
Armin Mehdipour ${ }^{1}$, Hoda Rashidi Nia ${ }^{2}$ \\ ${ }^{1}$ Bauhaus University Weimar, Weimar, Gemany \\ ${ }^{2}$ Anhalt University of Applied Sciences, Bernburg, Germany \\ Email: armin.mehdipour@gmail.com, hoda_r nia@yahoo.com
}

Received 20 January 2014; revised 5 February 2014; accepted 28 February 2014

Copyright (C) 2014 by authors and Scientific Research Publishing Inc.

This work is licensed under the Creative Commons Attribution International License (CC BY). http://creativecommons.org/licenses/by/4.0/

(c) (1) Open Access

\begin{abstract}
At the present time brownfield sites do not have a common definition yet. Each nation has already defined the term Brownfield based on their prioritized targets due to their diverse organizational, geographical, social and economic statuses. In Iranian context, any types of previously developed land-whether contaminated or not-and old urban property that its existence has perceived negative influences on the coherence of the surrounding land are defined as a brownfield site. These sites are mostly recognized as inner-city urban fabrics affected by former industrial and military actions that have considerable potential for regeneration practice. Mehrabad airport, as the third oldest airport in Iran, is currently dealing with various problems and constraints that not only put this immense urban space through adverse condition but also caused considerable difficulties for the surrounding residential neighborhoods. This article is basically intended to explore the recent environmental, physical and socio-economic problems of Mehrabad airport in order to raise the question as to whether this airport can be viewed as being a brownfield site or not.
\end{abstract}

\section{Keywords}

Brownfield; Mehrabad Airport; Environmental Problems; Physical Constraints; Socio-Economic Problems

\section{Introduction}

The formation of airports in Iran is accompanied by the emergence of aviation industry in this country in 1923. The first airport in Iran is Ghaleh Morghi airport constructed in 1923 with the purpose of supporting military activities. This airport is currently closed and in 2011, Tehran Municipality decided to allocate the remained land for construction of Velayat Park and a new highway. The next airport built in Iran was Doshan-Tapeh on the west of Tehran which only included a flat land prepared for take-off and landing small aircraft propellers. This airport is still being used by The Islamic Republic of Iran Air Force (IRIAF) for the military flights with small 
aircrafts (MTUD, 2013).

Mehrabad is the name of a village where the airport was built at that time. Nonetheless, Mehrabad village no longer exists due to the rapid expansion of the city of Tehran. The increasing number of international and domestic flights in Mehrabad—as the only airport within the city of Tehran — created a wide range of problems during the past decades which forced the government to consider the capability of replacing the airport. The necessity of constructing a major international airport in Tehran drew the attention of the authorities, aviation industry policy makers, urban planners as well as the country's plan and budget organization to meet the international and domestic needs in the late 60's. Meanwhile, the existence of technical and operational limitations in Mehrabad airport accelerated the urgency of creating a new airport in Tehran. Hence, Imam Khomeini International Airport (IKIA) was finally built and started operation in 2004.

Since the establishment of Mehrabad airport in 1938 until the official opening of Imam Khomeini International Airport (IKIA) in 2004, Mehrabad had been regarded as the main airport with the largest number of flights in Iran. After the initial opening of IKIA, almost the whole international flights of Tehran have been moved from Mehrabad to IKA except the small number of pilgrimage flights.

At the first sight, it might seem unusual to consider an airport as a brownfield site, especially when it is still covering enormous number of flights. But rather, due to the existing environmental, physical and socio-economic problems at Mehrabad airport, this article will try to go through all these problems and weaknesses in order to pose this question as to whether or not this wide industrialized area can be deemed to be a brownfield site.

\section{Physical Constraints at and around Mehrabad Airport}

Tehran has been one of the fastest growing Middle Eastern metropolises in the past decades. This growth in population has been accompanied with rapid development of the city, leading to a large increase in the number of densely populated areas which substantially changed the structure of the city of Tehran.

In 1939 Mehrabad airport was built in a small village called Mehrabad with a suitable distance from the city of Tehran. At that time, the whole area around the airport comprised a vast uninhabited land and the extent of surrounding open space seemed to be adequate for the limited number of flights. But shortly thereafter rapid housing development resulted from population growth transformed the former deserted land into the dense residential neighborhoods.

\subsection{Proximity to Residential Neighborhoods}

At the present time, Mehrabad airport is located in close proximity to surrounding residential areas so that the distance between the airport runway and closest neighborhoods including Hashemi, Moein, Houshyar, Dampezeshki and Dastgheib is only $250 \mathrm{~m}$ (Figure 1).

That is almost common throughout the world to consider a sufficient barrier between airports and settlements. For example, in the US, each county has their own ordinance established for airport zoning called Airport Overlay District (AOD). AOD is a proposed zoning designation that places restrictions and standards on prop-

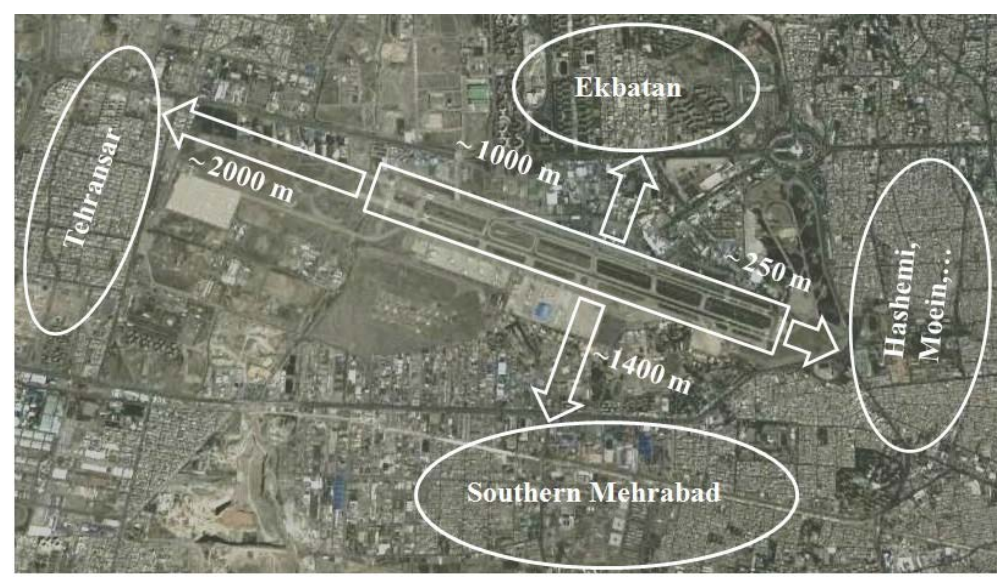

Figure 1. The minimum distance from airport runway to surrounding neighborhoods. 
erty located in close proximity to airports with the purpose of protecting the public health, safety and welfare in the vicinity airport area (AMEND, 2008). The application of AOD basically determines what kind of land uses and buildings shall be allocated around the airport. Further, it regulates and restricts the heights of constructed properties. Based on a report recently released by The Ministry of Transportation and Urban Development (MTUD, 2013), Mehrabad Airport Overlay District is defined in three following zones:

1) Zone I-The eastern part of the airport runway en route to approach/departure surface. A considerable number of buildings can be seen in this zone which have not been constructed based on local urban standards and are basically inconsistent with community character of the surrounding residential areas.

2) Zone II-The areas in lateral directions, especially eastern neighborhoods where buildings height must not exceed the general standards.

3) Zone III-The regions that encompass a number of constructions which must be compatible with the primary function of the airport (Figure 2).

In essence, Airport Overlay Districts (AOD) ordinances are created in most developed and developing countries to define a structure for further physical development around airports. In other words, these regulations are generally prepared before the development process starts. While, the recent AOD determined by MTUD reveals basic needs for enormous physical alternations at and around Mehrabad airport which is mainly resulted from close proximity to residential areas. In fact, it seems that this problem should have been paid attention before the excessive expansion of surrounding dwellings, since the whole neighborhoods are overloaded with dense settlements nowadays. Meanwhile, owing to the low level of living space per capita in district 9 (an average of about 11 square meters) it is expected that the expansion of residential areas around the airport will significantly increase in a few years (PMD9).

\subsection{Traffic Congestion}

Traffic and air pollution are two majorproblems in the city of Tehran so that this city is presently known as one the most traffic-congested and smog-filled cities in the world. Municipal district 9 in Tehran is also counted as an area that is currently dealing with many traffic problems. The reason is mainly due to the location of Mehrabad airport and Azadi square as two crowded areas in this district. The massive and heavy traffic around Mehrabad airport has not only created difficulties for residents in the district, but also it has extremely presented problems for transportation of passengers from and into the airport. The traffic circulation is very slow around Mehrabad airport, especially in Karaj special highway where the vehicles pass through the airport with a great difficulty (Figure 3(a)). This problem also hinders the transportation systems in surrounding residential neighborhoods, especially in eastern and northern areas. In general, the traffic problem of district 9 caused by Mehrabad airport can be considered because of two main reasons:

1) A solid and impenetrable boundary around the airport area; which imposes extreme restriction on traffic circulation near the airport, Azadi square and subsequently surrounding residential neighborhoods. This boundary turned the airport into an isolated urban area (Figure 3(b)).

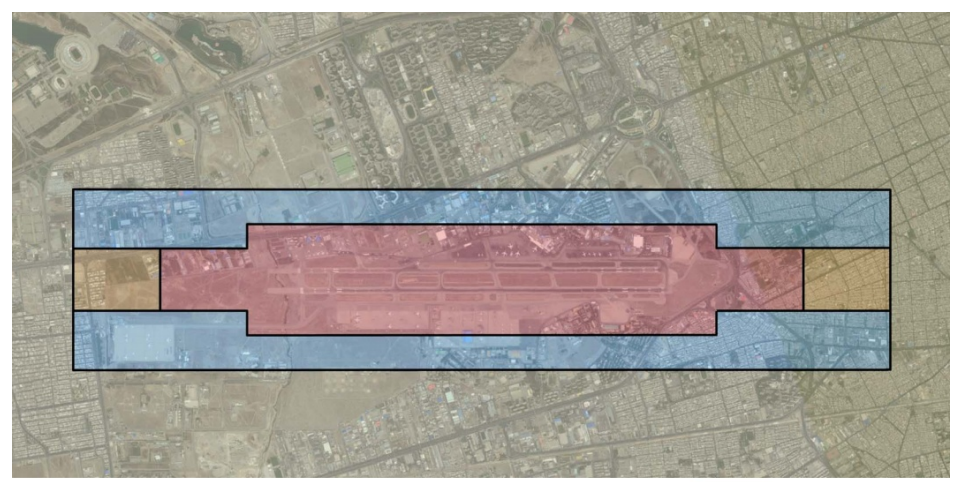

ZONE I

ZONE II

ZONE III

Figure 2. Mehrabad airport overlay district. 


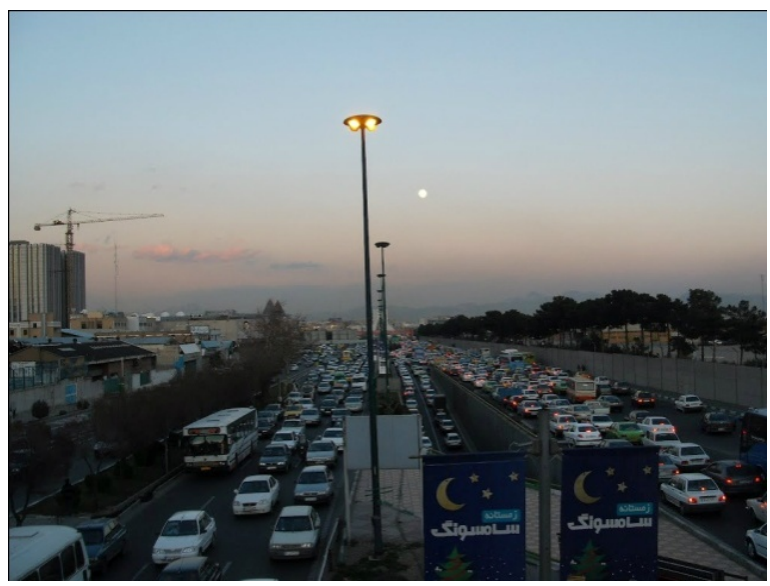

(a)

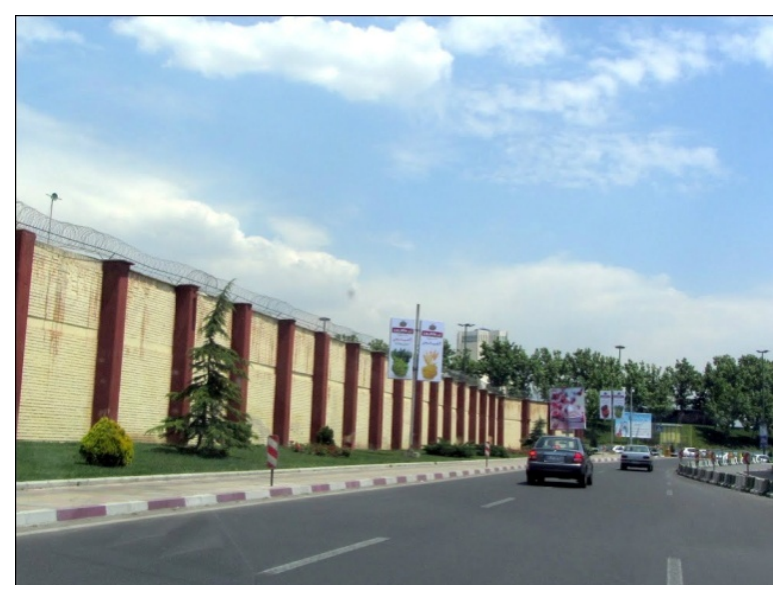

(b)

Figure 3. (a) Massive traffic jam in Karaj special road; (b) The long solid wall wrapping the whole airport area.

2) Practical impossibility to connect surrounding districts; the accessibility to the airport is completely inflexible. There is only two access to the airport in the northeast where a busy intersection between Azadi square, Karaj special road and Ayatollah-Saeidi highway is located. Meanwhile, there is no feasibility to allocate more accessibility for the airport since the majority of airport land is under military control — mainly southern partsin which any types of external intervention is highly restricted.

\section{Environmental Problems of Mehrabad Airport}

As noted before, the airport land use is not only limited to the flight services, but also the majority of the area is presently under the utilization of military parts which all together lead to extensive ecological problems. Meanwhile, the current industrial activities_principally due to aviation industries-at Mehrabad airport is another reason which has been found to cause serious environmental damages.

\subsection{Air Pollution}

One of the main environmental problems as a result of the existence of Mehrabad airport concerns air pollution. This pollution is mainly from the emissions of fly ash, dust, gases or other forms of emissions. In general, the air pollution generated by aviation industry and airport's activities could be viewed in two sorts:

1) Active air pollution; resulted from emission of dangerous chemicals to the air through burning of fossil fuels used by aircrafts and several industrial areas at the airport (Carbon dioxide and other greenhouse gases generated by burning fossil fuels are deemed to be one of the main causes of global warming).

2) Passive air pollution; caused by the ground traffic that coming in and out to the airport (buses, taxis, cars) which actually produces more pollution than the aircraft. Nonetheless, US research demonstrates that air pollution from cars and industry has been decreasing while aircraft continue to emit more ground level ozone precursors (Volatile Organic Compounds or VOCs and nitrogen oxides or NOx) with each passing year (Natural Resources Defense Council, 1996). It is estimated that about 4460 people die annually from diseases resulting from air pollution in Tehran (MHME, 2011). Meanwhile, another statistic shows that approximately 25\% of air pollution in the city of Tehran is only caused by the existence of Mehrabad Airport (MIMT, 2012). In other words, approximately 3 people daily lose their lives due to the air pollution-related diseases generated by aviation and industrial activities at Mehrabad airport.

\subsection{Noise Pollution}

Aircraft noise is considered as the principal concern at Mehrabad airport. The number of people exposed to noise problems around the airport is extremely high so that noise pollution has already created serious disturbances for the surrounding residential neighborhoods which are located in close proximity to the airport.

Based on the International law aircrafts are not allowed to create public nuisance to people during takeoff and 
landing. But unfortunately, since the majority of aircrafts at Mehrabad airport are old and do not have standard conditions, they relatively produce the maximum noise pollution. This matter has a negative influence over the quality of life of local people around the airport (this will be more discussed in socio-economic section).

The selection of a particular measure of noise can affect the extent to which level of noise is recognized as a problem (Whitelegg, 2000). In 1972, Orange County Health Department published a report which demonstrates different noise levels accepted by people without undue complaint in different locations. According to this report, the bearable noise range for people who live in urban areas is 35 - $55 \mathrm{~dB}$ (Table 1).

Based on another report (Navard, Gharkhlou, \& Norouzi, 2009), district 9 of Tehran municipality is divided into three areas based on noise pollution assessment:

1) Very dangerous and dangerous areas (75 - $85 \mathrm{~dB})$ : Mehrabad airport and parts of Terminals

2) Crucial areas (60 - $75 \mathrm{~dB}$ ): Southern part of Mehrabad airport

3) Areas that exceed standard limit ( 45 - $60 \mathrm{~dB}$ ): other neighborhoods of municipal district 9

In accordance with this report, it is relatively asserted that the whole areas in district 9 are in grave danger of noise pollution. Meanwhile, with respect to the close proximity of the airport and its terminals to the eastern and southeastern dwellings, the noise level must be considered in the urban residential category. By means of this fact, the intensity of noise at Mehrabad airport ( $60-85 \mathrm{~dB}$ ) is approximately 2 times more than the standard level (35 - $55 \mathrm{~dB}$ ) which obviously states the severity of noise pollution generated by the airport.

\section{Socio-Economic Problems of the Airport}

The most enormous socio-economic problems caused by Mehrabad airport are closely associated with physical and environmental matters. Indeed, there have been many socio-economic consequences arisen from the mentioned environmental degradation like noise and air pollution, as well as the physical deficiencies such as traffic problems and close proximity to the airport which yielded dissatisfaction and complaints of local residents. Today, residents in neighboring communities around Mehrabad airport are experiencing insanitary conditions regarding quality of life gains. This particularly includes acute health and comfort effects linked to the industrial and aviation activities of the airport. For instance, with respect to Orange County Health Department Report's report and considering the intensity of noise pollution generated by Mehrabad airport (60 - $85 \mathrm{~dB}$ ), this fact can be reflected that the local people around Mehrabad airport are in exposure to serious diseases such as hearing loss and extra-auditory physiological effects (Table 2).

Meanwhile, in 2002 another study was conducted by Bernhard Greiser for the Umwelbundesamt to assess the noise influence of Cologne airport on the surrounding residential areas. His study shows that aircraft noise with minimum level of $60 \mathrm{~dB}$ (the same minimum level of noise volume at Mehrabad airport) can extremely increase the cardiovascular disease by $61 \%$ in men and $80 \%$ in women (Bartsch, 2009).

Although public health and comfort in district 9 of Tehran are adversely affected by environmental and physical damages caused by Mehrabad airport, many economic constraints might be also created (See Table 3).

\section{Table 1. Acceptable noise volume in different locations.}

\begin{tabular}{ccc}
\hline Location & Day dB (A) & Night dB (A) \\
\hline Rural residential & $35-40$ & $25-35$ \\
Suburban residential & $40-50$ & $30-40$ \\
Urban residential & $45-55$ & $35-45$ \\
Commercial & $55-65$ & $45-55$ \\
Industrial & $60-70$ & $50-60$ \\
\hline
\end{tabular}

(Source: Orange County Health Department Report, 1972).

Table 2. The effects of different noise levels on human health.

\begin{tabular}{cc}
\hline Harmful effects & Noise levels dB (A) \\
Hearing loss & $75-85$ \\
Extra-auditory physiological effects & $65-75$ \\
Speech interference & $50-60$ \\
Interruption of sleep & $45-50$ \\
\hline
\end{tabular}

(Source: Orange County Health Department Report, 1972). 
Table 3. The existing problems and constraints at Mehrabad airport.

\begin{tabular}{ll}
\hline - Unfavorable transportation network and services that created heavy traffic, especially in northern \\
and eastern neighborhoods \\
- Proximity to residential areas and impossibility to develop the existing infrastructures due to the \\
restricted land of the airport area \\
- Old buildings and infrastructures \\
- Air pollution as active and passive sorts \\
- Noise Pollution coming from frequent takeoff and landing of aircrafts \\
ENVIRONMENTAL PROBLEMS - De-icing chemical pollution, which is more dangerous for the surrounding residential neighborhoods \\
- Pecause of the insufficient barrier \\
- Reor and old drainage system that has caused deep cracks on the landing field \\
- Increased defensive health expenditures of the citizens as a result of increasing pollution \\
SOCIO-ECONOMIC PROBLEMS - Insufficient allocation of required resources for the local people, especially because of massive \\
subsidies to aviation \\
- long-term negative effect on the airport’s earnings situation due to the rapid reduction of flights \\
\hline
\end{tabular}

Since there is no explicit market for environmental goods, the economic valuation of ecological damages like noise and air pollution are not simple or straightforward (Nelson, 2008). But at least, the adverse effects of these environmental destructions on human health would cause costs that are of relevant concern for the affected individuals and the entire economic system of the neighborhood (Getzner, 2012).

\section{Conclusions}

In exploration of various constraints at Mehrabad airport, it can be surely stated that the current situation of this isolated inner-city airport is incompatible with tripe bottom line approach that transferred the whole area to an unsustainable level. In fact, one of the main purposes of this article was to draw attention to the problems faced by local people around the airport. Table 3 summarizes the existing constraints and problems that Mehrabad airport is experiencing at the present time.

However, the complexity of partnerships and collaboration between principal sectors like Iranian government authorities and military forces has made it difficult to provide a practical answer to all these problems. This can be justified within Iranian urban development planning theory and practice where the role of private sectors is very slender.

It can be definitely stated that Mehrabad airport, as a developed urban area, has already created numerous physical, environmental, social and economic destructions for surrounding neighborhoods. Based on the respective attributes of brownfield site in Iran and with respect to the whole problems discussed in this article, Mehrabad airport is identified as a brownfield site which is in urgent need of substantial intervention.

On the plus side, the accumulation of dwellings in district 9 and inappropriate distribution of settlement patterns in this district prevent any sort of further development around Mehrabad airport. Based on a comprehensive plan to reduce environmental pollution in big cities, The Ministry of Transportation and Urban Development (MTUD) has been given the responsibility for shifting all flights from Mehrabad airport to Imam Khomeini International Airport (IKIA) until the end of the "fifth development plan"1 (ICANA, 2011). However, owing to current infrastructural constraints at IKIA such as the long distance to the city and week public transportation system, the process of airport transfer will definitely last for a while.

\section{References}

AMEND (2008). Cumberland County Zoning Ordinance. AOD Amendment. Article II P08-39.

Bartsch, M. (2009). Tödlicher Lärm (Deadly Noise). DER SPIEGEL, Nr. 51, 45 (German).

Getzner, M., \& Zak, D. (2012). Health Impacts of Noise Pollution around Airports: Economic Valuation and Transferability. Vienna University of Technology, Centre of Public Finance and Infrastructure Policy. Environmental Health—Emerging Issues and Practice.

\footnotetext{
${ }^{1}$ After the Islamic revolution in Iran, a five-year plan was drafted by the central government with the aim of economic, social and cultural development of the country. This plan is upgraded every five years by the government and must be approved by the parliament. As a result of that, in 2010 the fifth development plan was announced by the government and subsequently, one year later, approved by the Iranian parliament (ICARC, 2011). This plan is valid from 2011 to 2015 and all its contents must be implemented during this period.
} 
MHME (2011). Portal of Ministry of Health and Medical Education (Persian). http://www.behdasht.gov.ir/

MIMT (2012). Portal of Ministry of Industry, Mine and Trade (Persian). http://www.mimt.gov.ir/

MTUD (2013). Ministry of Transportation and Urban Development (in Cooperation with Imen Rah Consulting Engineers). Mehrabad International Airport Master Plan Review. Chapter 1. P.1 (Persian).

Natural Resources Defense Council (1996). Flying off Course. Environmental Impacts of America's Airports. Washington DC: NRDC.

Navard, M. \& Gharkhlou, M. \& Norouzi, M. (2009). The Evaluation and Location of Green Spaces in District 9 of Tehran Municipality. Journal of Practical Research on Geographical Sciences, 11.

Nelson, J.P. (2008). Hedonic Property Value Studies of Transportation Noise: Aircraft and Road Traffic. In A. Baranzini, J. Ramirez, C. Schaerer, \& P. Thalmann (Eds.), Hedonic Methods in Housing Markets: Pricing Environmental Amenities and Segregation (pp. 57-82), New York: Springer. http://dx.doi.org/10.1007/978-0-387-76815-1_4

PMD9. Portal of Municipal District 9 in Tehran (Persian): http://region9.tehran.ir/

Whitelegg, J. (2000). Aviation: The Social, Economic and Environmental Impact of Flying. London: Stockholm Environment Institute, University of York, The Ashden Trust. 